\title{
Protoplast isolation and development of a transient expression system for sweet cherry (Prunus avium L.)
}

\author{
Liping Yao ${ }^{\text {a }}$, Xiong Liao ${ }^{a}$, Zhizhe Gan ${ }^{\text {a }}$, Xiang Peng ${ }^{\text {a }}$, Peng Wang ${ }^{\text {a }}$, Shaojuan $\mathrm{Li}^{\mathrm{a}}$ and Tianhong Li ${ }^{\mathrm{a}}$ b,* \\ ${ }^{a}$ Department of Fruit Science, College of Horticulture, China Agricultural University, 2 Yuanmingyuan West \\ Road, Haidian District, Beijing 100193, People's Republic of China \\ ${ }^{\mathrm{b}}$ Beijing Collaborative Innovation Center for Eco-environmental Improvement with Forestry and Fruit Trees, \\ Beijing 102206, People's Republic of China \\ ${ }^{*}$ Corresponding author. Tel.: +86 01062733957; fax: +86 01062733957 \\ E-mail addresses: lpy106080@163.com (L.-p.Yao) and lith@cau.edu.cn (T.-h.Li)
}

\section{A B S T R A C T}

Transient gene expression in plant protoplasts is a powerful tool for analyzing gene function and for performing biotechnical manipulations. Here we report the isolation of viable protoplasts from the fruit flesh of sweet cherry (Prunus avium L.) cv. Hong Deng and their polyethylene glycol (PEG)-mediated transient transfection using green fluorescent protein (GFP) as a marker gene. We investigated the main factors affecting the efficacy of protoplast isolation and transfection, including the composition of the enzymolysis solution, enzymolysis time, $\mathrm{pH}$ of the enzymolysis solution, PEG concentration, and transfection time. Protoplast isolation was optimal when the tissue was incubated in enzymolysis solution composed of $1.0 \%$ Cellulase R-10, $0.5 \%$ Pectolase Y-23, and 0.6 M mannitol ( $\mathrm{pH} 5.8$ ) for $18 \mathrm{~h}$, resulting in a protoplast yield of $4.3 \times 10^{6}$ protoplasts $/ \mathrm{g}$ fresh weight $[\mathrm{FW}]$ and viability of $84.1 \%$. Protoplast transformation efficiency was measured by transient expression of the GFP reporter gene, and transformation efficiency was highest when protoplasts were incubated in transfection medium containing 40\% PEG for $15 \mathrm{~min}$. Collectively, 
this work describes an efficient protoplast isolation and protoplast transient expression system that can be used to facilitate molecular biology research in sweet cherry.

Keywords: Sweet cherry; Callus; Protoplast; Transient expression; Subcellular localization

\section{Introduction}

Transient gene expression is a powerful tool for studying the functions of exogenous genes, the subcellular localization of proteins, protein-protein interactions, protein complexes, and gene silencing in vivo. Three transient transformation strategies have been established in plants, including biolistic bombardment (Ueki et al., 2009), infiltration with Agrobacterium tumefaciens (agroinfiltration) (Song and Sink, 2005; Andrieu et al., 2012), and polyethylene glycol (PEG)-mediated transformation of protoplasts (Yoo et al., 2007; Cao et al., 2014). These transient expression methods are simple, fast, safe, and efficient and express the foreign gene but do not integrate it into the genome, typically resulting in high expression levels. Limitations of biolistic bombardment are high cost and low transformation efficiency. Whereas Agrobacterium-mediated transient expression is rapid, inexpensive, and easy to perform, it is limited by the physiological responses of the target plant and environmental factors that affect A. tumefaciens virulence (Wroblewski et al., 2005).

PEG-mediated protoplast transformation offers a high transformation efficiency and is widely used in somatic hybridization, microprotoplast-mediated chromosome transfer, organelle or DNA microinjection, electroporation, gene transactivation, and nucleocytoplasmic protein trafficking (Lin et al., 2014; Rezazadeh and Niedz, 2015). This approach requires high-quality protoplasts and optimization of transformation methods. Protocols for culturing protoplasts from many fruit 
species have been established (Ochatt, 1992; Mills and Hammerschlag, 1994; Witjaksono et al., 1998; Ara et al., 2000; Yu et al., 2000; Haicour et al., 2009; Rezazadeh and Niedz, 2015; Wang et al., 2015). Protoplasts have yet to be isolated from the fruit of sweet cherry ( $P$. avium $\mathrm{L}$ ), the major cultivated type of cherry, despite several reports of in vitro regeneration from shoots (Tang et al., 2002; Matt and Jehle, 2005), one report of protoplast isolation from leaf mesophyll tissues and cell suspension cultures (Ochatt et al., 1987) of colt cherry (P. avium $\times$ pseudocerasus). Furthermore, there is no report of the PEG-mediated protoplast transformation of sweet cherry. Sweet cherry $(P$. avium $\mathrm{L})$ is an economically important crop that is widely cultivated in temperate regions throughout the world due to its appealing color, delicious taste, and nutritional value (Wei et al., 2015). In addition, cherry fruits are suitable for processing into various candy and milk products, canning, and juice, liqueur, and jam production (Radičević et al., 2011).

Isolating large numbers of viable protoplasts and developing methods for high transformation efficiency are two crucial steps for establishing a reliable protoplast transient expression system. These two steps are affected by the composition of the enzymolysis solution, enzymolysis time, $\mathrm{pH}$ of the enzymolysis solution, PEG concentration, and transfection time. The enzymolysis solution consists of a mixture of osmotic stabilizers and lytic enzymes. Mannitol (Hidaka and Omura, 1992; Niedz, 1993; Rezazadeh and Niedz, 2015) and sorbitol (Jumin and Nito, 1996; Ortin-Parraga and Burgos, 2003) or a combination of the two (Myers et al., 1989; Ara et al., 2000) are often used as osmotic stabilizers for the isolation and culture of protoplasts (Rezazadeh and Niedz, 2015), whereas the lytic enzymes cellulase, pectinase 1, 3-glucanase, and chitinase are frequently used to digest cell walls during protoplast isolation. Different lytic enzymes have different effects on cell walls degradation, and it is necessary to test each combination of enzyme 
used. Enzymolysis time affects protoplast isolation; prolonging the period of enzymolysis increases the ratio of protoplasts formed, up to a point. After a certain period, additional enzymolysis results in protoplast breakage. The $\mathrm{pH}$ value of the enzymolysis solution affects enzyme activity and thus protoplast isolation. Due to its ability to increase cell wall permeability. PEG is regarded as an effective protoplast transfection agent (Huang et al., 2013). The concentration of PEG affects the transformation efficiency and cell viability. Transfection time affects the transformation efficiency; excessive periods of transfection may damage protoplasts and reduce the transformation efficiency (Shillito et al., 1985). Furthermore, the proportion and concentration of the osmotic stabilizers and lytic enzymes influence the establishment of an efficient protoplast isolation system. Factorial experimental designs have been used to optimize factors for highly efficient protoplast isolation (Ochatt, 1992; Witjaksono et al., 1998; Jiang et al., 2015; Masani et al., 2014); however, a limitation of factorial experimental design is that the effects of the proportion and concentration of compounds are not considered (Anderson and Whitcomb, 2002; Rezazadeh and Niedz, 2015).

In the present study, we set up an efficient protocol to isolate protoplasts from suspension-cultured cells from the fruit flesh of sweet cherry and developed a transient expression system using GFP as a reporter gene. Furthermore, we optimized the factors influence the efficacy of protoplast isolation and transfection, including enzymolysis solution component concentration, enzymolysis time, the $\mathrm{pH}$ value of enzymolysis solution, $\mathrm{PEG}$ concentration, and transfection time. This is the first report of the transient expression of a gene in sweet cherry protoplasts. Our results lay the foundation for future molecular biology studies in sweet cherry.

\section{Materials and methods}




\subsection{The preparation of cherry berry suspension-cultured cells}

Sweet cherry (P. avium L.) cv. Hong Deng was used in this study. Ten-year-old trees were maintained in Beijing Institute of Forestry and Pomology, People's Republic of China. Cherry berries were harvested at 34 days after full bloom, washed with tap water for $30 \mathrm{~min}$, sterilized with 5\% (v/v) sodium hypochlorite for 13 min, followed by $75 \%$ ethanol for $30 \mathrm{~s}$, and then rinsed in sterile distilled water three times. The peel was removed and the fruit flesh was diced into 8 $\mathrm{mm}^{3}$ cubes and placed in MS medium (with $2.0 \mathrm{mg} / \mathrm{L}$ 6-BA, $1.0 \mathrm{mg} / \mathrm{L}$ 2, 4-D, $30 \mathrm{~g} / \mathrm{L}$ sucrose, and 7.5 g/L agar) at $25 \pm 1^{\circ} \mathrm{C}$. Callus was produced and subcultured every 2-3 weeks. Cell suspension culture was based on MS medium supplemented with $1.0 \mathrm{mg} / \mathrm{L}$ 6-BA, $0.3 \mathrm{mg} / \mathrm{L}$ 2, 4-D, and 3.0 $\mathrm{mg} / \mathrm{L}$ Vitamin $\mathrm{C}(\mathrm{Vc})$. The culture was incubated at $80 \mathrm{rpm} / \mathrm{min}$ on a rotary shaker, and the culture was subcultured once a week.

\subsection{Protoplast isolation}

Protoplast isolation procedures were carried out as previously described (Ochatt et al., 1987; Yoo et al., 2007; Huang et al., 2013; Wang et al., 2015) with several modifications. Before enzymatic digestion, suspension cells were plasymolyzed in CPW13M [CPW salts with 13\% (w/v) mannitol] solution for $1 \mathrm{~h}$ at $23^{\circ} \mathrm{C}$, with shaking at $50 \mathrm{rpm} / \mathrm{min}$. The enzyme solution contained bovine serum albumin [BSA, 0.1\% (w/v)], MES Free Acid [0.1\% (w/v)], polyvinylpyrrolidone [PVP K-30, 1.0\% (w/v)], mannitol, and different concentrations of Cellulase R-10 (Japan Yakult) and Pectolase Y-23 (Japan Yakult), as shown in Table 1. To optimize the concentration of mannitol used in the enzyme solution, different concentrations of mannitol were tested $(0.3,0.4,0.5,0.6$, 0.7 , and $0.8 \mathrm{M})$. To optimize enzymolysis time, different digestion times were tested $(12,14,16$, 
18, and $20 \mathrm{~h}$ ). To optimize the $\mathrm{pH}$ of the enzymolysis solution, different $\mathrm{pH}$ values of the enzymolysis solution were tested $(5.2,5.4,5.6,5.8,6.0$, and 6.2). All the experiments were repeated three times. One milliliter of the cell suspension was incubated in $10 \mathrm{ml}$ enzymolysis solution at $23^{\circ} \mathrm{C}$, with rotation $(50 \mathrm{rpm} / \mathrm{min})$. After digestion, the mixture was filtered through 74 $\mu \mathrm{m}$ sieves. The filtrate was centrifuged at $900 \mathrm{rpm}$ for $5 \mathrm{~min}$, the supernatant was discarded, and the sediment was resuspended in $3 \mathrm{ml}$ CPW13M [CPW salts with 13\% (w/v) mannitol] solution. Then, $6 \mathrm{ml}$ CPW25S [CPW salts with 25\% (w/v) sucrose] was added to a new $10 \mathrm{ml}$ centrifuge tube, supplemented with all the protoplast suspensions, and centrifuged at $900 \mathrm{rpm} / \mathrm{min}$ for $5 \mathrm{~min}$ (Marchant et al., 1997; Hao et al., 2013). Protoplasts were carefully removed from the interface of the solutions, then the protoplasts were washed three times with CPW13M and then centrifuged at $900 \mathrm{rpm}$ for $5 \mathrm{~min}$, the supernatant was discarded, and then the protoplasts were resuspended in MMG (400 mM mannitol, $30 \mathrm{mM} \mathrm{MgCI} 2,4 \mathrm{mM}$ MES) solution at a final concentration of $4 \times 10^{6}$ protoplasts $/ \mathrm{ml}$ for transient transfection.

The yield of purified protoplasts was determined using a hematocytometer under a general light microscope (XSZ-G) and their viability was assessed using Trypan blue. For each sample, the count was performed three times. Protoplast viability was tested using 4\% Trypan blue (Kamlesh et al., 1984). The Trypan blue solution was prepared by mixing $1 \mathrm{ml}$ Trypan blue with 9 $\mathrm{ml}$ PBS at a 1:10 dilution. Briefly, $20 \mu 1$ Trypan blue solution was added to $180 \mu 1$ of protoplast suspensions to a final concentration of $0.04 \%$, the samples were incubated in darkness at $25^{\circ} \mathrm{C}$ for $5 \mathrm{~min}$, and protoplast viability was assessed using a microscope (Nikon ECLIPSE Ti, Japan), according to the following equation: protoplast viability $(\%)=$ number of protoplast not stained blue in view / number of total Protoplast in view $\times 100 \%$. 
Table 1 Combinations of Cellulase R-10 and Pectolase Y-23 used in enzymolysis solution

\begin{tabular}{|c|c|c|}
\hline Treatment no. & Cellulase R-10 (\%) & Pectolase Y-23 (\%) \\
\hline 1 & 0.5 & 0.25 \\
\hline 2 & 1.0 & 0.25 \\
\hline 3 & 1.5 & 0.25 \\
\hline 4 & 0.5 & 0.50 \\
\hline 5 & 1.0 & 0.50 \\
\hline 6 & 1.5 & 0.50 \\
\hline 7 & 0.5 & 0.75 \\
\hline 8 & 1.0 & 0.75 \\
\hline 9 & 1.5 & 0.75 \\
\hline
\end{tabular}

BSA, MES, PVP K-30, and mannitol were dissolved in CPW [containing (mg/L): $\mathrm{KH}_{2} \mathrm{PO}_{4}(27.2), \mathrm{KNO}_{3}(101)$, $\mathrm{MgSO}_{4}(120), \mathrm{CaCI}_{2}$ (1118), $\left.\mathrm{KI}(0.16), \mathrm{CuSO}_{4} 5 \mathrm{H}_{2} \mathrm{O}(0.025)\right]$ solution at $55^{\circ} \mathrm{C}$ for $15 \mathrm{~min}$, and then Cellulase $\mathrm{R}-10$ and Pectolase Y-23 were added. The solution was filtered through a 0.22 um syringe filter, and then stored in $4^{\circ} \mathrm{C}$ for later use.

\subsection{PEG-mediated protoplast transfection}

PEG-mediated DNA transfection was performed as previously described (Yoo et al., 2007) with some modifications. PEG4000- $\mathrm{Ca}^{2+}$ transfection solution was freshly prepared by adding PEG4000 (10, 20, 30, 40, and 50\%, w/v) in $\mathrm{ddH}_{2} \mathrm{O}$ containing $200 \mathrm{mM}$ mannitol and $100 \mathrm{mM}$ 
$\mathrm{CaCl}_{2}$, and the solution was incubated at $55^{\circ} \mathrm{C}$ for $10 \mathrm{~min}$ to enhance solubility. Isolated protoplasts were kept on ice for $30 \mathrm{~min}$, then centrifuged at $900 \mathrm{rpm}$ for $5 \mathrm{~min}$. The supernatant was removed and the protoplasts were resuspended in MMG solution (400 mM mannitol, $4 \mathrm{mM}$ MES, $30 \mathrm{mM} \mathrm{MgCl} 2$ ). Then, $15 \mu \mathrm{g}$ pE3025-GFP plasmid DNA (Chung et al., 2005) was added to $100 \mu 1$ protoplasts and the samples were mixed gently. A volume of $110 \mu 1 \mathrm{PEG} 4000-\mathrm{Ca}^{2+}$ was added and the samples were mixed gently to obtain a PEG4000 final concentration of approximately 5-25\% (replicated three times) (Burris et al., 2015). To optimize the transfection time, the protoplasts were incubated for 5, 10, 15, 20, and $25 \mathrm{~min}$ in darkness at room temperature. After incubation, $440 \mu \mathrm{l} \mathrm{CPW13M}$ solution was added to stop the transfection. The mixture was centrifuged at $900 \mathrm{rpm}$ for $5 \mathrm{~min}$ and the protoplasts were gently resuspended in $1 \mathrm{ml} \mathrm{W} 5$ solution (Yoo et al., 2007).

The transfected protoplasts were incubated at $23^{\circ} \mathrm{C}$ in darkness for $18-20 \mathrm{~h}$, centrifuged at 900 rpm for $5 \mathrm{~min}$, and then resuspended in an appropriate amount of W5 solution. Fluorescence was observed using a laser scanning confocal microscope (OLYMPUS FLUVIEW FV1000, Japan) and the number of green fluorescent protoplasts was scored to evaluate transformation efficiency, according to the following equation: transformation efficiency $(\%)=$ (number of fluorescent protoplasts in view/total number of protoplasts in view) $\times 100 \%$. E3025-PacMYBA-GFP construct was generated by Shen et al. (2014). Subcellular localization was performed using a laser scanning confocal microscope (OLYMPUS FLUVIEW FV1000, Japan).

\subsection{Data analysis}

All experiments were performed three times and data were shown as mean \pm SE from three 
independent experiments. All data were analyzed using analysis of variance (ANOVA) in SPSS software Version 20.0 (SPSS, Inc., Chicago, IL, USA), and a probability values of $\mathrm{P} \leq 0.05$ were considered significant.

\section{Results}

\subsection{Callus induction from sweet cherry fruit flesh}

To induce callus from the fruit flesh of sweet cherry, the fruit flesh was placed on MS medium (with $2.0 \mathrm{mg} / \mathrm{L}$ 6-BA, $1.0 \mathrm{mg} / \mathrm{L}$ 2, 4-D, $30 \mathrm{~g} / \mathrm{L}$ sucrose, and $7.5 \mathrm{~g} / \mathrm{L}$ agar) (Fig. 1). After one week of cultivation, callus was produced from the explants. Four weeks later, the callus was subcultured on a weekly basis, and used to prepare suspension-cultured cells.
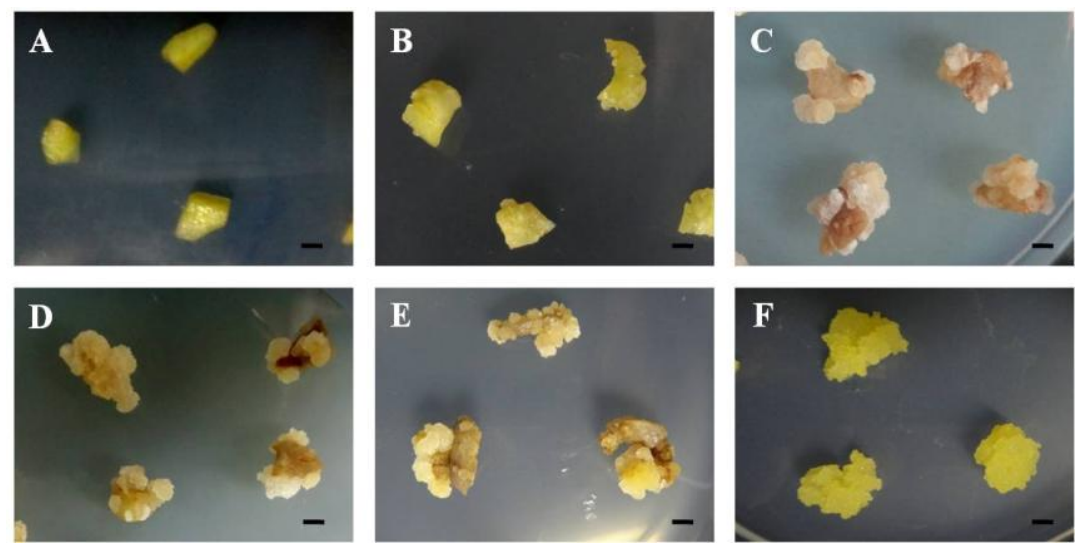

Fig. 1 The induction of callus using sweet cherry fruit flesh. (A) Fruit flesh was placed on MS medium (with 2.0

mg/L 6-BA, 1.0 mg/L 2, 4-D, $30 \mathrm{~g} / \mathrm{L}$ sucrose, and $7.5 \mathrm{~g} / \mathrm{L}$ agar). Callus produced after One (B), Two (C), Three

(D), and Four (E) weeks. (F) Callus after several rounds of subculture. Bars, $2 \mathrm{~mm}$.

3.2 Enzymolysis optimization for protoplast isolation from sweet cherry suspension-cultured cells

To improve the yield and viability of the released protoplasts, we next optimized the 
enzymolysis system. Table 1 shows the concentrations of Cellulase R-10 and Pectolase Y-23 used in the enzymolysis system to isolate the protoplasts of sweet cherry cell suspension. The highest yield of protoplasts, i.e., $4.1 \times 10^{6}$ protoplasts/g FW, with viability of $79.8 \%$, was obtained when using a combination of 1.0\% (w/v) Cellulase R-10 and 0.5\% (w/v) Pectolase Y-23 (Fig. 2).

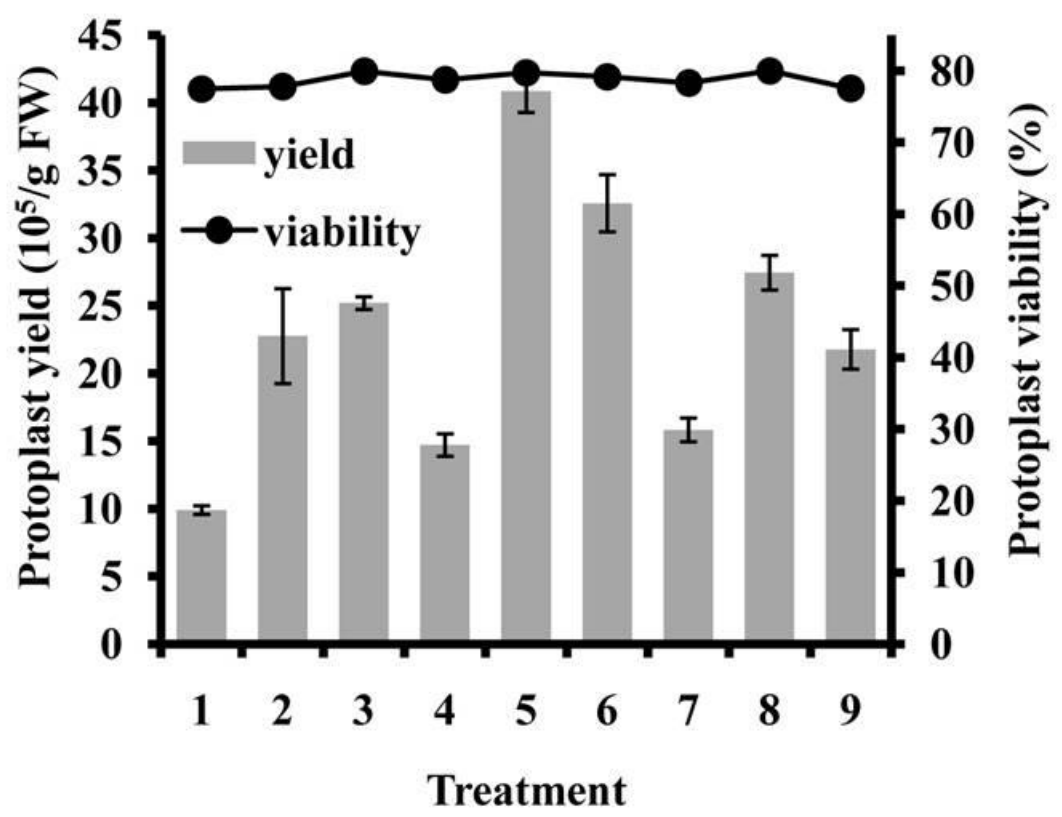

Fig. 2 Effects of enzyme composition on protoplast yield and viability of 'Hong Deng' suspension-cultured cells.

Enzyme concentrations in treatment 1-9 are given in Table 1. Bars represent standard errors (SEs). The experiments were repeated three times.

3.3 The effects of mannitol concentration, enzymolysis time and $\mathrm{pH}$ on fruit flesh of sweet cherry suspension-cultured cells protoplast isolation

To optimize the concentration of mannitol in the enzymolysis solution, we evaluated the effect of $0.3,0.4,0.5,0.6,0.7$, and $0.8 \mathrm{M}$ mannitol (Fig. 3A and 3B). Protoplast yield was greatest, at $3.8 \times 10^{6}$ protoplasts/g $\mathrm{FW}$, with a viability of $80.4 \%$, when using $0.6 \mathrm{M}$ mannitol (Fig. 3B). Increasing the concentration of mannitol beyond that point tended to decrease protoplast yield and 
viability (Fig. 3B) and increase debris. We also found that high concentrations of mannitol affected the protoplast viability; when the concentration of mannitol reached 0.7 and $0.8 \mathrm{M}$, the viability of protoplasts decreased, and the proportion of broken protoplasts increased.

To study the effects of enzymolysis time on protoplast yield and viability, we evaluated the effect of $12,14,16,18$ and $20 \mathrm{~h}$ of enzymolysis. Increasing of enzymolysis time from 12 to $18 \mathrm{~h}$ resulted in an increase in protoplast production from $1.5 \times 10^{6}$ to $3.9 \times 10^{6}$ protoplasts/g FW. When the enzymolysis time was increased to $20 \mathrm{~h}$, protoplast production decreased to $1.8 \times 10^{6}$ protoplasts/g FW. Furthermore, when the enzymolysis time was $12,14,16$, and $18 \mathrm{~h}$, the viability was around $80 \%$, but decreased to $60.7 \%$ at $20 \mathrm{~h}$ (Fig. 3C). These results indicate that $18 \mathrm{~h}$ of enzymolysis is optimal for protoplast yield and viability.

To determine the relationship between $\mathrm{pH}$ of the enzymolysis solution and protoplast yield and viability, we evaluated the effect of various $\mathrm{pH}$ values (i.e., 5.2, 5.4, 5.6, 5.8, 6.0, and 6.2). Increasing the $\mathrm{pH}$ of the enzymolysis solution from 5.2 to 5.8 resulted in an increase in protoplast yield and viability from $1.1 \times 10^{6}$ protoplasts/g FW and $21.23 \%$ to $4.3 \times 10^{6}$ protoplast $/ \mathrm{g} \mathrm{FW}$ and $84.3 \%$, respectively, and the optimal $\mathrm{pH}$ value for the enzymolysis solution was 5.8. Increasing the $\mathrm{pH}$ further to 6.0 and 6.2, resulted in a decrease in protoplast yield and viability (Fig. 3D). Thus, the optimal $\mathrm{pH}$ of the enzymolysis solution is 5.8 . 

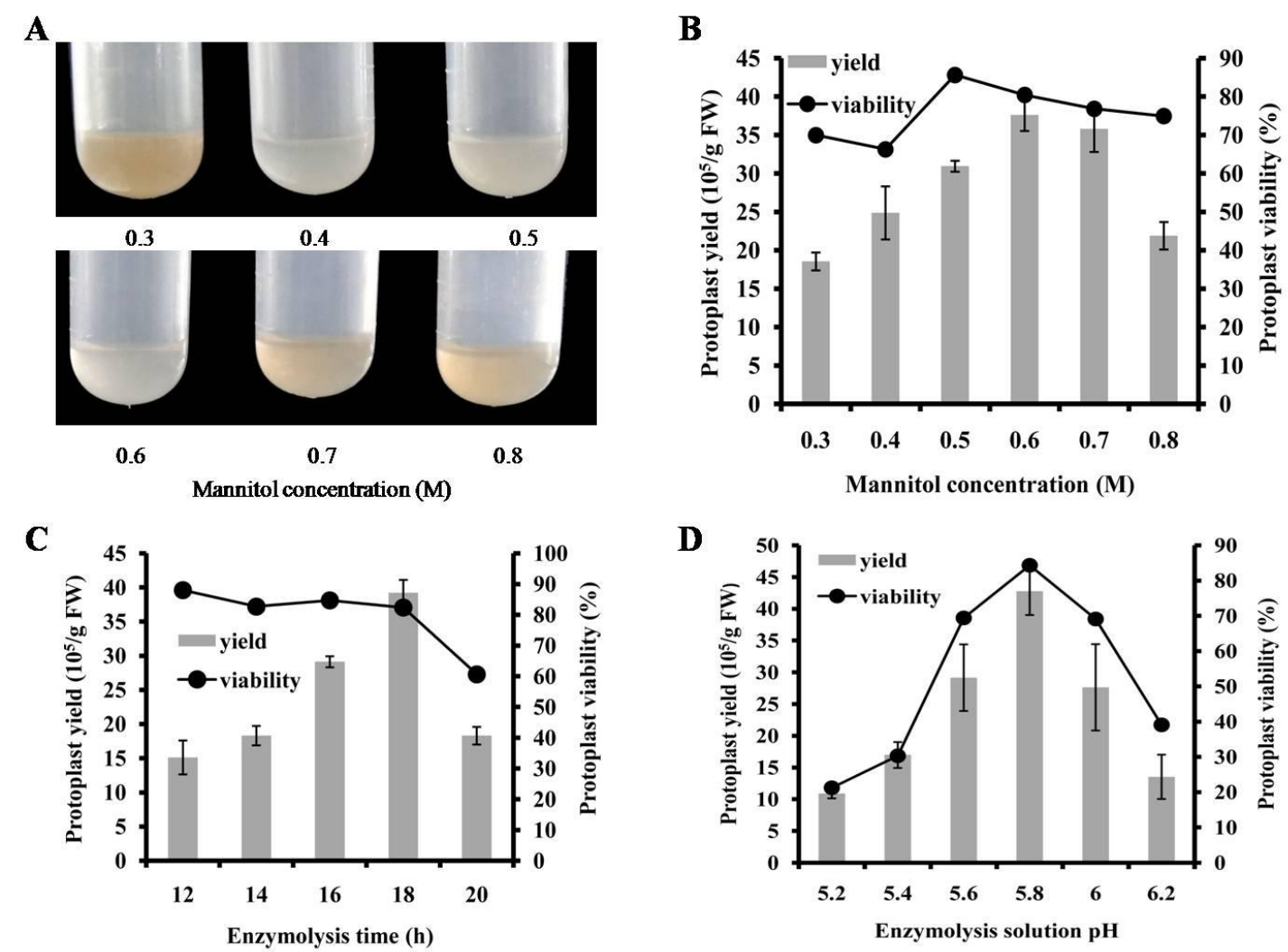

Fig. 3 Optimizing enzymolysis conditions. Effects of mannitol concentration in the enzymolysis solution (A and B)

and enzymolysis time (C) and $\mathrm{pH}(\mathrm{D})$ on the yield and viability of protoplasts isolated from suspension-cultured cells of sweet cherry fruit flesh. Bars represent standard errors (SEs). The experiments were repeated three times.

Overall, we found that the optimal concentration of Cellulase R-10 and Pectolase Y-23 in the enzymolysis system was $1.0 \%(\mathrm{w} / \mathrm{v})$ and $0.5 \%(\mathrm{w} / \mathrm{v})$, respectively, and that the optimal mannitol concentration, enzymolysis time, and $\mathrm{pH}$ value in the enzymolysis solution was $0.6 \mathrm{M}, 18 \mathrm{~h}$, and 5.8, respectively. To reduce the production of debris, we purified protoplasts by interface separation (Fig. 4). Protoplast viabitity was observed by using a microscope (Nikon ECLIPSE Ti, Japan) (Fig. 5). 

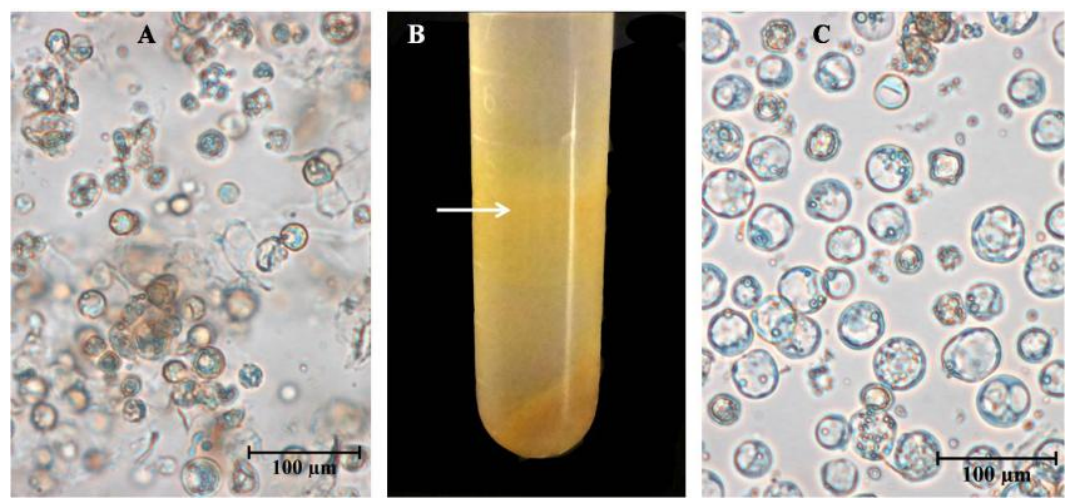

Fig. 4 Purification of protoplasts by interface separation. (A) Protoplast isolation from suspension-cultured cells.

(B) Purification of protoplasts by interface separation. (C) Protoplasts after purification.

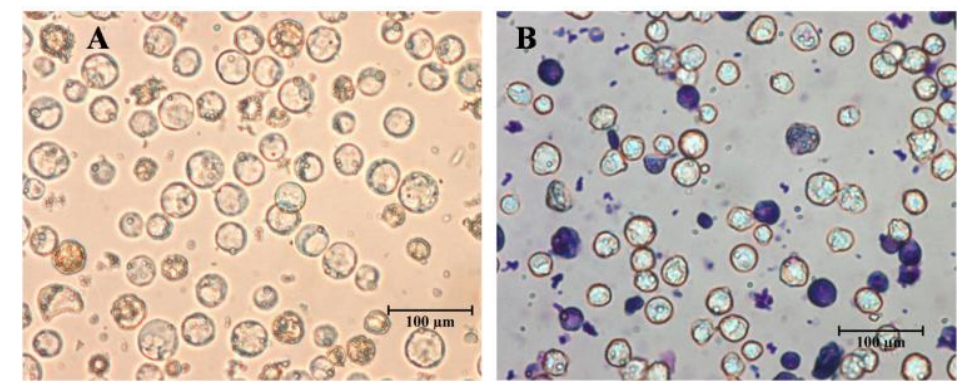

Fig. 5 The viability of protoplasts isolated from suspension-cultured cells of sweet cherry fruit flesh. The suspension-cultured cells were digested for $18 \mathrm{~h}$ in enzymolysis solution containing Cellulase R-10 1.0\% (w/v), Pectolase Y-23 0.5\% (w/v) and $0.6 \mathrm{~mol} / \mathrm{L}$ mannitol, at $\mathrm{pH}$ 5.8. (A) Control. (B) Over $80 \%$ of the protoplasts were viable (only dead cells stain with Trypan blue).

\subsection{Effects of PEG concentration and transfection time on protoplast transformation efficiency}

We used the transient expression vector pE3025 to study the effects of PEG4000 concentration and transfection time on fruit flesh of sweet cherry protoplast transformation efficiency. To determine the effects of PEG concentration on protoplast transformation efficiency, we examined the effect of varying the PEG concentration from 10 to $50 \%(10,20,30,40$, and $50 \%$, respectively). We found that increasing the PEG concentration from 10 to $40 \%$ resulted in an 
increase in protoplast transformation efficiency (Fig. 6A). When the PEG concentration was increased to $50 \%$, no significant $(\mathrm{P} \leq 0.05)$ transformation efficiency increase was observed and abnormal protoplasts and debris were observed. Therefore, the optimal concentration of PEG4000 for transformation and the efficiency was $40 \%$ and $33.4 \%$, respectively.

To optimize the transfection time, we analyzed the effects of $5,10,15,20$, and $25 \mathrm{~min}$ of transfection time. We found that increasing the transfection time from 5 to 15 min resulted in an increase in transformation efficiency from 17.6 to $34.1 \%$. When the transfection time was further increased to 20 and $25 \mathrm{~min}$, a decrease in transformation efficiency was observed (Fig. 6B). Thus, the optimal transfection time was $15 \mathrm{~min}$.
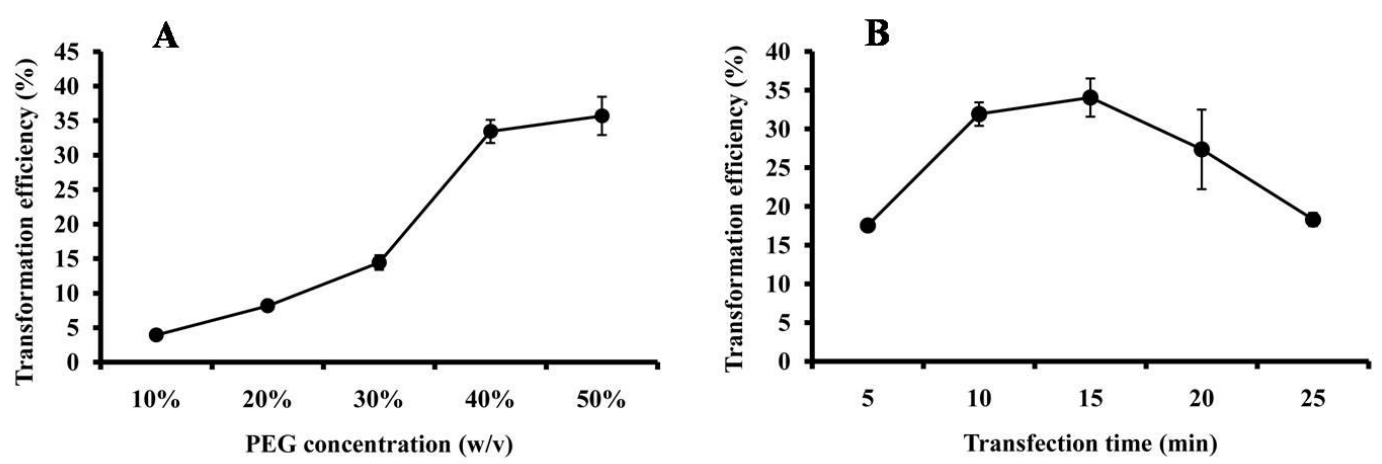

Fig. 6 Transformation optimization. (A) The effect of different PEG4000 concentrations (10, 20, 30, 40 and 50\% w/v) on transformation efficiency. (B) The effect of transfection time (5, 10, 15, 20, and $25 \mathrm{~min}$ ) on transformation efficiency when protoplasts were transfected in $40 \%$ PEG4000. Bars represent standard errors (SEs). The experiments were repeated three times.

\subsection{Transient expression in protoplasts isolated from suspension-cultured sweet cherry cells}

In a previous study, we characterized a sweet cherry $(P$. avium L.) cv. Hong Deng transcription factor, PacMYBA, using an Arabidopsis protoplast transformation system, we demonstrated that 
PacMYBA is localized to the nucleus (Shen et al., 2014). In this study, we isolated protoplasts from the fruit flesh of sweet cherry cv. Hong Deng and established a protoplast transformation system to verify the subcellular localization of PacMYBA in sweet cherry. Green fluorescence was detected specifically in the nucleus, with no fluorescence in the cytomembrane and cytoplasm (Fig. 7).

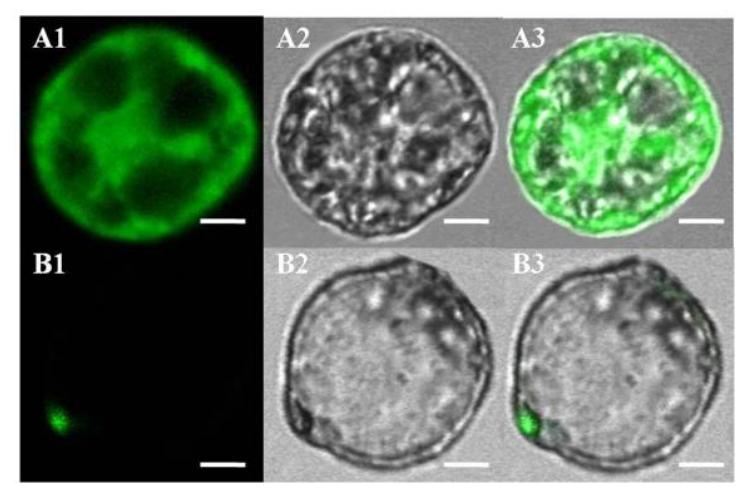

Fig. 7 Subcellular localization analysis of PacMYBA in sweet cherry protoplasts isolated from suspension-cultured cells. Transient expression of E3025-PacMYBA-GFP fusion protein, showing localization to the nucleus. (A1) The expression of E3025-GFP in dark field. (B1) The expression of E3025-PacMYBA-GFP in dark field. (A2 and B2) Protoplasts in bright field. (A3) The merged image of A1 and A2. (B3) The merged image of B1 and B2. Bars, $15 \mu \mathrm{m}$.

\section{Discussion}

Transient gene expression techniques are available for the rapid analysis of gene function in plants. Protoplast transient expression systems have been developed for many fruit species, including banana (Musa spp.) (Sagi et al., 1994), Kiwifruit (Actinidia deliciosa) (Raquel and Oliveira, 1996), apple (Malus domestica Borkh.) (Maddumage et al., 2002), orange (Citrus sinensis L.) (Niedz et al., 2003), peach (P. persica L.) (Honda and Moriguchi, 2006), and grape 
(Vitis vinifera L.) (Wang et al., 2015). We present here the first report of protoplast isolation and PEG-mediated protoplast transformation in sweet cherry. In our current study, we isolated protoplasts from sweet cherry callus and developed a PEG-mediated transient transfection system optimized for enzymolysis solution composition, enzymolysis time, the $\mathrm{pH}$ of the enzymolysis solution, PEG concentration, and transfection time.

The type and concentration of enzyme used to isolate protoplasts from suspension-cultured cells is selected based on the species used. Cellulase degrades cell walls by modifying celluloses, lichenin, and cereal $\beta$-D-glucans (Sweat and Bodri, 2014), whereas pectolase breaks down the pectins in cell walls. Cellulase R-10 and Pectolase Y-23 are commonly used to isolate protoplasts from suspension cells in wheat (Triticum aestivum) (Kenzhebaeva et al., 2001), tobacco (Cynodon dactylon L.) (Li et al., 2006), populus (Populus alba L.) (Jing et al., 2007), and apple (Wei et al., 2009). We isolated protoplasts from suspension-cultured cells by evaluating which concentations of Cellulase R-10 and Pectolase Y-23, resulted in the greatest yield of protoplasts. A similar optimization of enzyme concentration was performed previously (Rezazadeh and Niedz, 2015). Qiao et al. (1998) indicated that increasing the concentration of cellulase from 1 to $2 \%$ resulted in a sharp decrease in protoplast yield in poplar. Kativat et al. (2012) showed that the protoplast yield of sunflower (Helianthus annuus) differed when using 0.5, 1.0, and 1.5\% cellulase. In this study, we found that protoplast yield was greatest when using a Pectolase Y-23 concentration of $0.50 \%$ coupled with $1.0 \%$ Cellulase R-10.

Mannitol is an osmotic stabilizer that is frequently used to provide the required osmolarity for protoplast isolation (Hidaka and Omura, 1992; Niedz, 1993; Rezazadeh and Niedz, 2015), maintain the balance between the interior and exterior osmotic pressure of protoplasts, prevent 
protoplasts from rupturing, and support enzyme activity (Zhao et al., 2004). In this study, we found that a number of protoplasts burst in the presence of $0.3 \mathrm{M}$ mannitol due to low exterior solution pressure, while protoplasts ruptured at $0.8 \mathrm{M}$ mannitol due to high exterior solution pressure. The maximal protoplast yield and viability were obtained at $0.6 \mathrm{M}$ mannitol. Enzymolysis time also affects protoplast isolation, and since this parameter depends on the species being studied, it needs to be optimized empirically (Yoo et al., 2007). Appropriate enzymolysis time increases forming the protoplast (Jiang et al., 2015), while long time enzymolysis periods cause a decrease in protoplast formation and viability, due to breaking of the protoplast and reduction of protoplast activity. In this study, we found that an enzymolysis time of longer than 20 $\mathrm{h}$ resulted in a decrease of protoplast yield and viability, and that the optimal enzymolysis time was $18 \mathrm{~h}$. The $\mathrm{pH}$ of the enzymolysis solution indirectly affects the isolation of protoplast from suspension-cultured cells by affecting enzyme activity. In this study, protoplast yield and viability were greatest when the $\mathrm{pH}$ was close to 5.8 .

Furthermore, we developed a PEG-mediated transfection system for introducing exogenous DNA into protoplasts, and assessed the transformation efficiency using GFP as a marker. Transfection efficiency can be optimized by altering the PEG concentration (Negrutiu et al., 1987; Damm et al., 1989; Armstrong et al., 1990; Lee et al., 2001) and transfection time. We found that 40\% (w/v) PEG is optimal for transformation of protoplasts derived from sweet cherry fruit flesh. A high PEG concentration may inhibit transfection and cause a significant loss of protoplast viability. We found that 50\% (w/v) PEG resulted in a decrease in protoplast viability and caused clumping of protoplasts, thus cause difficulty to identify individual protoplast producing GFP. The transfection time also affects transformation efficiency; for instance, a 30-min PEG treatment was 
shown to be optimal for grapevine protoplast transformation (Wang et al., 2015). Our results indicated that a 15-min PEG treatment is optimal for transformation of protoplasts isolated from the fruit flesh of sweet cherry. When the PEG treatment was increased beyond 15 minutes, such as transfection time of $25 \mathrm{~min}$, the transformation efficiency decreased to $18.3 \%$.

In conclusion, we developed procedures to isolate protoplasts from the fruit flesh of sweet cherry suspension-cultured cells and to transiently transfect these protoplasts. To our knowledge, this is the first report describing the isolation of protoplasts from the sweet cherry and of the PEG-mediated protoplast transfection of these protoplasts using GFP as a reporter gene. This protoplast transient expression system can be used to study the subcellular localization of proteins, protein-protein interactions, and regulatory mechanisms that affect fruit quality. The protoplast transient expression efficiency is $34.1 \%$, which is lower than that reported for Arabidopsis (Yoo et al., 2007). Future work is needed to improve the transformation efficiency further. Nonetheless, our procedure provides a rapid and convenient transient expression system that can be used to analyze sweet cherry gene functions.

\section{Acknowledgements}

We thank Professor Tao Wang (China Agricultural University, China) for the gift of the pE3025-GFP plasmid, Dr. Bingbing Li (China Agricultural University, China) for continuous support and Dr. Kathleen Farguharson for English revision. This research was supported by the Special Fund for Forest Scientific Research in the Public Interest [grant No. 201404720], the National Science Foundation Project [grant No. 31171938] and the Beijing Municipal Education Commission [grant No. CEFF-PXM2016_014207_000038]. 


\section{References}

Anderson, M.J., Whitcomb, P.J., 2002. Mixture DOE uncovers formulations quicker. Rubber Plast. News 32, 16-18.

Andrieu, A., Breitler, J.C., Siré, C., Meynard, D., Gantet P., Guiderdoni, E., 2012. An in planta, Agrobacterium-mediated transient gene expression method for inducing gene silencing in rice (Oryza sativa L.) leaves. Rice 5, 23-23.

Ara, H., Jaiswal, U., Jaiswal, V.S., 2000. Plant regeneration from protoplasts of mango (Mangifera indica L.) through somatic embryogenesis. Plant Cell Rep. 19, 622-627.

Armstrong, C.H., Petersen, W.L., Buchholz, W.G., Bowen, B.A., Sulc, S.L., 1990. Factors affecting PEG-mediated stable transformation of maize protoplasts. Plant Cell Rep. 9, 335-339.

Burris, K.P., Dlugosz, E.M., Grace Collins, A., Neal Stewart Jr, C., 2015. Development of a rapid, low-cost protoplasts transfection system for switchgrass (Panicum virgatum L.). Plant Cell Rep. 35, 693-704.

Cao, J.M., Yao, D.M., Lin, F., Jiang, M.Y., 2014. PEG-mediated transient gene expression and silencing system in maize mesophyll protplasts: a valuable tool for signal transduction system in maize. Acta Physiol. Plant. 36, 1271-1281.

Chung, S.M., Frankman, E.L., Tzfira, T., 2005. A versatile vector system for multiple gene expression in plants. Trends Plant Sci. 8, 357-361.

Damm, B, Schmidt, R., Willmitzer, L., 1989. Efficient transformation of Arabidopsis thaliana using direct gene transfer to protoplasts. Mol. Gen. Genet. 217, 6-12.

Haicour, R., Assani, A., Trang, V.B., Guedira, A., 2009. Protoplast isolation and culture for banana 
regeneration via somatic embryogenesis. Fruits 64, 261-269.

Hao, Y.Z., Yang, X.Y., Shi, Y.Z., Song, T., Xing, J., Marowitch, J., Chen, J.M., 2013. Magnetic gold nanoparticles as a vehicle for fluorescein isothiocyanate and DNA delivery into plant cells. Botany 7, 457-466.

Hidaka, T., Omura, M., 1992. Regeneration of somatic hybrid plants obtained by electrical fusion between satsuma mandarin (Citrus unshiu) and rough lemon (C. jambhiri) or Yuzu (C. junos). Jpn. J. Breed. 42, 79-89.

Honda, C., Moriguchi, T., 2006. High GUS expression in protoplasts isolated from immature peach fruits. Sci. Hortic. 109, 244-247.

Huang, H.Y., Wang, Z.Y., Cheng, J.T., Zhao, W.C., Li, Xin., Wang, H. Y., Zhang, Z.X., Sui, X.L., 2013. An efficient cucumber (Cucumis sativus L.) protoplasts isolation and transient expression system. Sci. Hortic. 150, 206-212.

Jiang, C.C., Qiu, S.S., Li, C.H., 2015. Optimization of protoplast formation, regeneration, and viability of myxobacteria. Adv. Chem. Sci. 4, 1-6.

Jing, Y.C., Kang, X.Y., Wang, J., Li, D.L., 2007. Isolation and purification of mesophyll protoplasts of Populus alba L. var. pyramidalis. Acta Bot. Boreali-Occidential Sinica. 03, $509-514$.

Jumin, H.B., Nito, N., 1996. Plant regeneration via somatic embryogenesis from protoplasts of six plant species related to Citrus. Plant Cell Rep. 15, 332-336.

Kamlesh, R.P., Narpat, S.S., Graeme, P.B., Trevor, A.T., 1984. Isolation and culture of protoplasts from cytoledons of Pinus coulteri D. Don. Plant Cell Tiss. Organ Cult. 3, 85-90.

Kativat, C., Poolsawat, O., Tantasawat, P.A., 2012. Optimization of factors for efficient isolation 
of protoplasts in sunflower (Helianthus annuus L.). Austr. J. Crop Sci. 6, 1004-1010.

Kenzhebaeva, S. S., Yamamoto, Y., Matsumoto, H., 2001. Aluminum-induced changes in cell-wall glycoproteins in the root tips of Al-tolerant and Al-sensitive wheat lines. Russian J. Plant Physiol. 48, 441-447.

Lee, S.H., Blackhall, N.W., Power, J.B., Cocking, E.C., Tepfer, D., Davey, M.R., 2001. Genetic and morphological transformation of rice with the rolA gene from the RiTL-DNA of Agrobacterium rhizogenes. Plant Sci. 161, 917-925.

Li, J., Guo, J., Xu, W., Ma, M., 2006. Enhanced cadmium accumulation in transgenic tobacco expressing the phytochelatin synthase gene of Cynodon dactylon L. J. Integr. Plant Biol. 48, 928-937.

Lin, Y.C., Li, W., Chen, H., Li, Q.Z., Sun, Y.H., Shi, R., Lin, C.Y. Wang, J.P., Chen, H.C., Chuang, L., Qu, G.Z., Sederoff, R.R., Chiang, V.L., 2014. A simple improved-throughput xylem protoplast system for studying wood formation. Nat. Protoc. 9, 2194-2205.

Maddumage, R., Fung, R.M.W., Weir, L., Ding, H., Simons, J.L., Allan, A.C., 2002. Efficient transient transformation of suspension culture-derived apple protoplasts. Plant Cell Tiss. Organ Cult. 70, 77-82.

Marchant, R., Davey, M.R., Power, J.B., 1997. Isolation and culture of mesophyll protoplasts from Rosa hybrid. Plant Cell Tiss. Organ Cult. 50, 131-134.

Masani, M.Y.A., Noll, G.A., Parveez, G.K.A., Sambanthamurthi, R., Prüfer, D., 2014. Efficient transformation of oil palm protoplasts by PEG-mediated transfection and DNA microinjection. PLoS One 9, e96831.

Matt, A., Jehle, J.A., 2005. In vitro plant regeneration from leaves and internode sections of sweet 
cherry cultivars (Prunus avium L.). Plant Cell Rep. 24, 468-476.

Mills, D., Hammerschlag, F.A., 1994. Isolation of cells and protoplasts from leaves of in vitro propagated peach (Prunus persica) plants. Plant Cell Tiss. Organ Cult. 36, 99-105.

Myers, J.R., Grosser, J., Taylor, N., Collins, G.B., 1989. Genotype-dependent whole plant regeneration from protoplasts of red clover (Trifolium pratense L.). Plant Cell Tiss. Organ Cult. 19, 113-127.

Negrutiu, I., Shillito, R., Potrykus, I., Biasini, G., Sala, F., 1987. Hydrib genes in the analysis of transformation conditions. Plant Mol. Biol. 8, 363-373.

Niedz, R.P., 1993. Culturing embryogenic protoplasts of 'Hamlin' sweet orange in calcium alginate beads. Plant Cell Tiss. Organ Cult. 34, 19-25.

Niedz, R.P., McKendree, W.L., Shatters Jr, R.C., 2003. Electroporation of embryogenic protoplasts of sweet orange (Citrus sinensis ( L.) Osbeck) and regeneration of transformed plants. In Vitro Cell. Dev. Biol. Plant. 39, 586-594.

Ochatt, S.J., 1992. The development of protoplast-to-tree system for Prunus cerasifera and Prunus spinosa. Plant Sci. 81, 253-259.

Ochatt, S.J., Cocking, E.C., Power, J.B., 1987. Isolation, culture and plant regeneration of colt cherry ( Prunus avium $\times$ pseudocerasus ) protoplasts. Plant Sci. 50, 139-143.

Ortin-Parraga, F., Burgos, L., 2003. Isolation and culture of mesophyll protoplast from apricot. J. Hort. Sci. Biotechnol. 78, 624-628.

Qiao, J., Kuroda, H., Hayashi, T., Sakai, F., 1998. Efficient plantlet regeneration from protoplasts isolated from suspension cultures of poplar (Populus alba L.). Plant Cell Rep. 17, 201-205.

Radičević, S., Cerović, R., Marić, S., Đorđević, M., 2011. Flowering time and incompatibility 
groups - Cultivar combination in commercial sweet cherry (Prunus avium L.) orchards. Genetika 43, 397-406.

Raquel, M.H., Oliveira, M.M., 1996. Kiwifruit leaf protoplasts competent for plant regeneration and direct DNA transfer. Plant Sci. 121, 107-114.

Rezazadeh, R., Niedz, R. P., 2015. Protoplast isolation and plant regeneration of guava (Psidium guajava L.) using experiments in mixture-amount design. Plant Cell Tiss. Organ Cult. 122, 585-604.

Sagi, L., Remy, S., Panis, B., Swennen, R., Volckaert, G., 1994. Transient gene expression in electroporated banana (Musa spp., cv. 'Bluggoe', ABB group) protoplasts isolated from regenerable embryogenetic cell suspensions. Plant Cell Rep. 13, 262-266.

Shen, X.J., Zhao, K., Liu, L.L., Zhang, K.C., Yuan, H.Z., Liao, X., Wang, Q., Guo, X.W., Li, F., Li, T.H., 2014. A role for PacMYBA in ABA-regulated anthocyanin biosynthesis in red-colored sweet cherry cv. Hong Deng (Punus avium L.). Plant Cell Physiol. 55, 862-880.

Shillito, R.D., Saul, M.W., Paszkowski, J., Müller, M., Potrykus, I., 1985. High efficiency direct gene transfer to plants. Nat. Biotechnol. 3, 1099-1103.

Song, G.Q., Sink, K.C., 2005. Optimizing shoot regeneration and transient expression factors for Agrobacterium tumefaciens transformation of sour cherry. Sci. Hortic. 106, 60-69.

Sweat, J., Bodri, B.S., 2014. Isolation of protoplasts from Nepenthes - a plant carnivore. Plant Tissue Cult. Biotech. 24, 93-100.

Tang, H., Ren, Z.L., Reustle, G., Krczal, G., 2002. Plant regeneration from leaves of sweet and sour cherry cultivars. Sci. Hortic. 93, 235-244. 
Ueki, S., Lacroix, B., Krichevsky, A., Lazarowitz, S.G., Citovsky, V., 2009. Functional transient genetic transformation of Arabidopsis leaves by biolistic bombardment. Nat. Protoc. 4, 71-77.

Wang, H.L., Wang, W., Zhan, J.C., Huang, W.D., Xu, H.Y., 2015. An efficient PEG-mediated transient gene expression system in grape protoplasts and its application in subcellular localization studies of flavonoids biosynthesis enzymes. Sci. Hortic. 191, 82-89.

Wei, H.R., Chen, X., Zong, X.J., Shu, H.R,, Gao, D.S., Liu, Q.Z., 2015. Comparative transcriptome analysis of genes involved in anthocyanin biosynthesis in the red and yellow fruits of sweet cherry (Prunus avium L.). PLoS One 10, e0121164.

Witjaksono, H., Litz, R.E., Grosser, J.W., 1998. Protoplast isolation, culture and somatic embryo regeneration in avocado (Persea americana Mill). Plant Cell Rep. 18, 235-242.

Wroblewski, T., Tomczak, A., Michelmore, R.W., 2005. Optimization of Agrobacterium -mediated transient assays of gene expression in lettuce, tomato and Arabidopsis. Plant Biotechnol. J. 3, 259-273.

Yoo, S.D., Cho, Y.H., Sheen, J., 2007. Arabidopsis mesophyll protoplasts: a versatile cell system for transient gene expression analysis. Nat. Protoc. 2, 1565-1572.

Yu, C., Chen, Z., Lu, L., Lin, J., 2000. Somatic embryogenesis and plant regeneration from litchi protoplasts isolated from embryogenic suspensions. Plant Cell Tiss. Organ Cult. 61, 51-58.

Zhao, K., Zhou, D.P., Ping, W.X., Ge, J.P., 2004. Study on the preparation and regeneration of protoplast from taxol-producing fungus Nodulisporium sylviforme. Nat. Sci. 2, 52-59. 